\title{
Antifungal resistance on Sporothrix species: an overview
}

\section{Stefanie Bressan Waller ${ }^{1}$ (D) Daiane Flores Dalla Lana ${ }^{2} \cdot$ Priscilla Maciel Quatrin $^{3} \cdot$ Marcos Roberto Alves Ferreira $^{4}$. Alexandre Meneghello Fuentefria ${ }^{5} \cdot$ Adelina Mezzari $^{5}$}

Received: 19 October 2019 / Accepted: 22 May 2020 / Published online: 31 May 2020

(C) Sociedade Brasileira de Microbiologia 2020

\begin{abstract}
Introduction The treatment of human and animal sporotrichosis is often performed with antifungal agents; however, the emergence of antifungal-resistant strains of Sporothrix species has been reported. We aimed to discuss the ability of Sporothrix species in developing resistance to the conventional antifungals and mechanisms for this.

Methodology Published data on databases (PubMed, Science Direct, Google Scholar) were investigated using a combination of keywords from 2008 to 2019 by the StArt tool.

Results The minimal inhibitory concentrations values based on the Clinical and Laboratory Standards Institute (CLSI) from eight references were classified according to the epidemiological cutoff values in wild-type or non-wild-type strains. In this way, nonwild-type S. schenckii and, mainly, S. brasiliensis isolates were recognized on itraconazole, amphotericin B, terbinafine, and voriconazole, which are strains that deserve more attention toward antifungal control, with a probable risk of mutation to antifungal resistance. Among the few reviewed studied on antifungal resistance, the melanin production capacity (DHN-melanin, L-DOPA melanin, and pyomelanin), the low genetic diversity due to the abnormal number of chromosomes, and the mutation in cytochrome $\mathrm{P} 450$ are some of the factors for developing resistance mechanism.

Conclusions The emergence of Sporothrix species with in vitro antifungal resistance was evidenced and the possible mechanisms for resistance development may be due to the melanin production capacity, genetic diversity and mutations in cytochrome P450. Further studies should be carried out targeting gene expression for the development of antifungal resistance on Sporothrix species in order to prospect new therapeutic targets for human and veterinary use.
\end{abstract}

Keywords Sporotrichosis $\cdot$ Sporothrix species $\cdot$ Antifungal resistance $\cdot$ Melanin $\cdot$ Genetic diversity $\cdot$ Mutation $\cdot$ Gene expression

Responsible Editor: Sandro Rogerio de Almeida.

Stefanie Bressan Waller

waller.stefanie@yahoo.com.br

1 Department of Preventive Veterinary, Faculty of Veterinary, Federal University of Pelotas, Pelotas, RS 96010-900, Brazil

2 Postgraduate Program in Pathology, Federal University of Health Sciences of Porto Alegre, Porto Alegre, RS, Brazil

3 Postgraduate Program in Agricultural and Environmental Microbiology, Federal University of Rio Grande do Sul, Porto Alegre, RS, Brazil

4 Biotechnology, Technological Development Center, Federal University of Pelotas, Pelotas, RS, Brazil

5 Department of Analysis, Faculty of Pharmacy, Federal University of Rio Grande do Sul, Porto Alegre, RS, Brazil

\section{Introduction}

Sporotrichosis is a fungal disease caused by the dimorphic species of the Sporothrix genus with a worldwide distribution, affecting both humans [1, 2] and animals [3, 4]. Among the species that most infect mammals, the clinical (pathogenic) clade refers to Sporothrix schenckii sensu stricto (s. str.), S. brasiliensis, S. globosa, and S. luriei, whereas Sporothrix mexicana belongs to the environmental clade [5].

Once a traumatic injury occurs with inoculation of Sporothrix conidia inside the skin, the clinical signs vary from fixed and multiple cutaneous to lympho-cutaneous and systemic forms [6], the worst presentations of which are often related to poor immunological conditions [7]. These factors can affect the healing using conventional therapy, which is recommended by performing the antifungal susceptibility assay for the choice of the antifungal agent and the effectiveness of the therapy. However, refractory cases to conventional therapies, such as itraconazole, have been reported, for example, in humans by 
S. schenckii [2] and by S. globosa [1], as well as in felines [8] by $S$. schenckii [9], and canines by $S$. brasiliensis [4]. This mini-review aimed to discuss the ability of Sporothrix species in developing resistance to antifungal agents.

\section{Research strategy}

Scientific studies were investigated by four independent examiners in the databases of PubMed, Science Direct, and Google Scholar from 2008 to 2019. For the research, the following keywords were used in two groups of combined keywords as a strategy: ["Sporothrix schenckii complex" or "sporotrichosis" or "Sporothrix"] and ["antifungal" or "antifungal susceptibility testing" or "antifungal resistance" or "resistance mechanism" or "melanin" or "mutation" or "gene expression"]. Studies on Sporothrix species from both human and animal sporotrichosis cases were included. No restriction of language was applied.
Reviews, meeting abstracts, chapter of books, as well as studies without in vitro antifungal susceptibility testing, such as molecular identification, the activity of plant extracts, or no antifungal resistance of Sporothrix species, were excluded (Fig. 1). The classification criteria of inclusion and exclusion were performed using the StArt (State of the Art through Systematic Review, version 2.3.4.2) tool. Regarding the antifungal susceptibility testing, only those that described lower minimal inhibitory concentration able to inhibit the fungal growth by $50 \%\left(\mathrm{MIC}_{50}\right)$ and $90 \%\left(\mathrm{MIC}_{90}\right)$ of the total isolates were included.

\section{In vitro antifungal resistance on Sporothrix species}

Standard guidelines of microdilution testing by Clinical and Laboratory Standard Institute (CLSI) [10] and European Committee for Antimicrobial Susceptibility Testing (EUCAST) [11] have shown the antifungal susceptibility profile of fungal species. In the last years, increasing reports of antifungal resistance have been related to Sporothrix species.

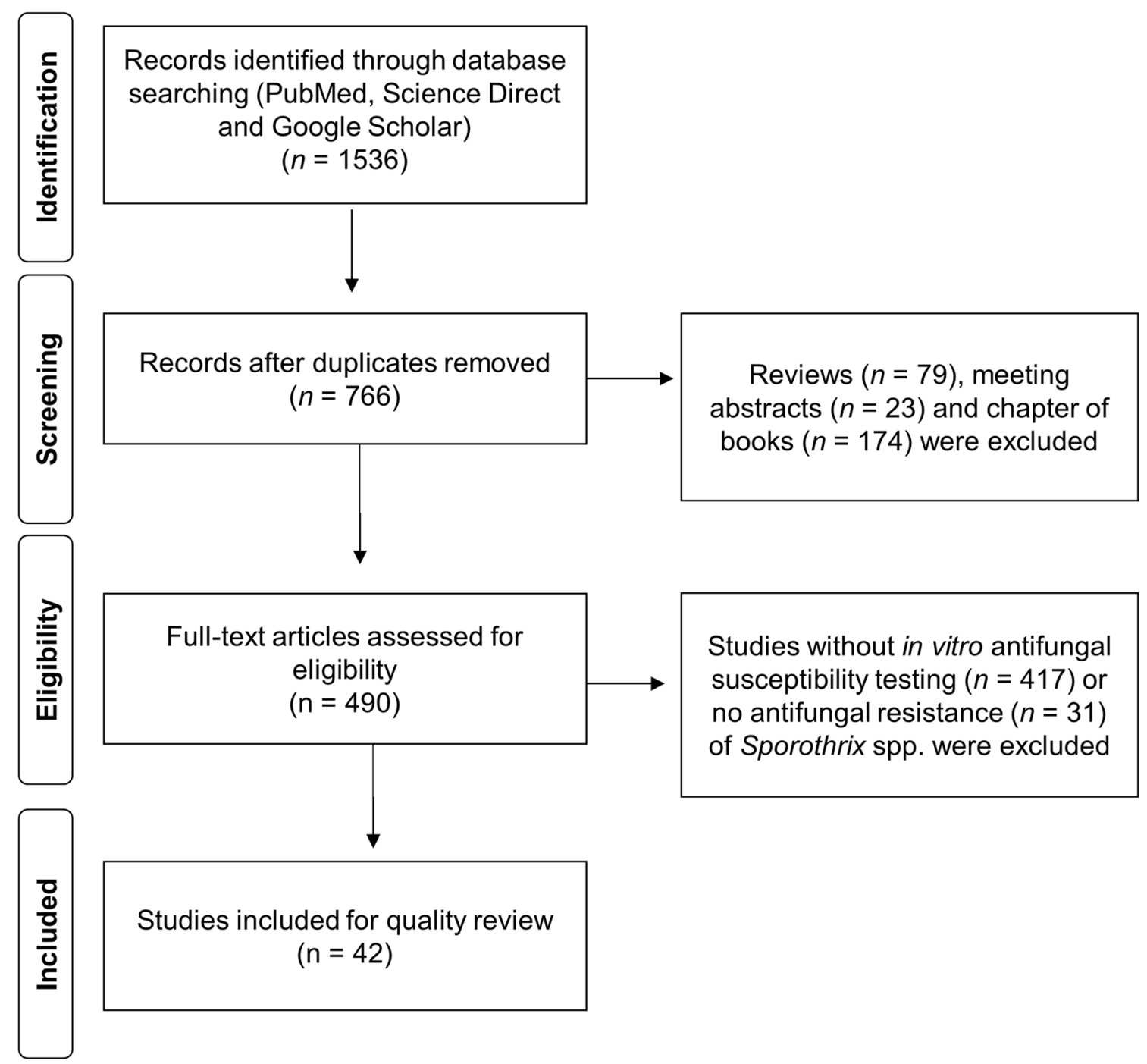

Fig. 1 Flowchart of research evidence and criteria for inclusion and exclusion of studies 
Studies have classified the antifungal susceptibility of S. schenckii, in which the minimal inhibitory concentrations (MICs) values equal to or higher than $8 \mu \mathrm{g} / \mathrm{mL}$ may be considered resistance. In this way, S. brasiliensis from humans [1, $2,12,13]$ and animal [13-15] cases has been described as itraconazole-resistant isolates.

Recently, Espinel-Ingroff et al. [3] characterized the epidemiological cutoff values (ECVs) based on CLSI MICs data of antifungal agents available from worldwide laboratories. The ECV allows identifying the non-wild-type (non-WT) Sporothrix species with reduced susceptibility to the antifungal agent due to acquired mutational or resistance mechanism from the wild-type (WT) isolates, which are the isolates with no acquired resistance mechanism. For S. schenckii and S. brasiliensis, the following ECVs to identify the WT strains and non-WT strains are presented in Table 1. In Table 2, we compiled the MIC values of S. schenckii and S. brasiliensis tested by eight manuscripts and classified them as non-WT and WT, based on the ECVs proposed by Espinel-Ingroff et al. [3].

According to Table 2, S. schenckii from worldwide and Brazil were classified as non-WT isolates when tested with itraconazole, due to the high $\mathrm{MIC}_{50}[15]$ and $\mathrm{MIC}_{90}[12,15]$, as well as with amphotericin B [12]. A similar finding was shown on the $\mathrm{MIC}_{90}$ of posaconazole against $S$. schenckii [16]. In turn, no $S$. schenckii isolates from Argentina were classified as non-WT among the tested antifungals [17].

Table 1 Epidemiological cutoff values (ECVs) of different antifungal agents for identifying the wild-type (WT) and non-wild-type (non-WT) strains of Sporothrix schenckii and Sporothrix brasiliensis, as proposed by Espinel-Ingroff et al. [3]*

\begin{tabular}{|c|c|c|c|}
\hline \multirow[t]{2}{*}{ Sporothrix species } & \multirow[t]{2}{*}{ Antifungal agents ${ }^{\dagger}$} & \multicolumn{2}{|l|}{ ECVs* } \\
\hline & & $\begin{array}{l}\text { WT } \\
(\mu \mathrm{g} / \mathrm{mL})\end{array}$ & Non-WT $(\mu \mathrm{g} / \mathrm{mL})^{\S}$ \\
\hline \multirow[t]{4}{*}{ S. schenckii } & AMB & $\leq 4$ & $>4$ \\
\hline & ITR & $\leq 2$ & $>2$ \\
\hline & POS & $\leq 2$ & $>2$ \\
\hline & VOR & $\leq 64$ & $>64$ \\
\hline \multirow[t]{6}{*}{ S. brasiliensis } & AMB & $\leq 4$ & $>4$ \\
\hline & ITR & $\leq 2$ & $>2$ \\
\hline & POS & $\leq 2$ & $>2$ \\
\hline & VOR & $\leq 32$ & $>32$ \\
\hline & KET & $\leq 2$ & $>2$ \\
\hline & TERB & $\leq 0.12$ & $>0.12$ \\
\hline
\end{tabular}

*ECVs values were based on minimal inhibitory concentrations (MIC) by microdilution test (M38-A2 guideline of the Clinical and Laboratory Standards Institute, CLSI [10], as proposed by Espinel-Ingroff et al. [3])

${ }^{\dagger} A M B$, amphotericin B; ITR, itraconazole; POS, posaconazole; VOR, voriconazole; $K T Z$, ketoconazole; $T R B$, terbinafine

${ }^{\S}$ Non-WT strains are recognized as Sporothrix spp. strains with reduced susceptibility to antifungals and, therefore, less likely to respond to the antifungal therapy
Among the studies that tested $S$. brasiliensis (Table 2), we observed non-WT isolates when tested with terbinafine $[14,16$, 17], voriconazole [18], and itraconazole [14, 19]. On the other hand, WT $S$. brasiliensis isolates were recognized to several antifungals [20,21]. Although itraconazole showed better activity against $S$. brasiliensis compared with $S$. schenckii $[12,16]$, high MIC values of this antifungal agent were recognized on animal-borne $S$. brasiliensis isolates from Southern Brazil [14, 19], which both $\mathrm{MIC}_{90}$ values classified these isolates as nonWT. Relating to terbinafine, high activity was shown against all Sporothrix species tested by Marimon et al. [16]. However, according to the ECVs proposed by Espinel-Ingroff et al. [3], the $\mathrm{MIC}_{90}$ values of this antifungal against $S$. brasiliensis were high, as well as those found on the $\mathrm{MIC}_{50}-\mathrm{MIC}_{90}$ values of terbinafine against $S$. brasiliensis isolates from Southern Brazil [14] and Argentina [17]. These S. brasiliensis were all classified as non-WT strains and, therefore, are also potential terbinafineresistant isolates. Besides that, $\mathrm{MIC}_{90}$ of voriconazole against S. brasiliensis [18] also was classified as non-WT.

Few studies using microdilution tests by the EUCAST were found on Sporothrix species. A study tested 91 Brazilian and Spanish $S$. schenckii strains by this guideline [22], showing an antifungal variability in this fungal species. Although this reference was not included in our study due to the lack of $\mathrm{MIC}_{50}$ and $\mathrm{MIC}_{90}$ values, Gutierrez-Galhardo et al. [22] showed the emergence of antifungal-resistant isolates of $S$. schenckii to fluconazole, itraconazole, voriconazole, posaconazole, and terbinafine. Considering the breakpoint [3], non-WT strains of S. schenckii to itraconazole (MIC range of 0.12 to $>8 \mu \mathrm{g} / \mathrm{mL}$ ) and posaconazole (MIC range of 0.06 to $>8 \mu \mathrm{g} / \mathrm{mL}$ ) are suggested, according to the susceptibility testing results using the EUCAST guideline and performed by Gutierrez-Galhardo et al. [22]. Besides that, an S. schenckii isolate from a cutaneous case of sporotrichosis in an immunocompetent patient showed high MIC values ( $>8 \mu \mathrm{g} / \mathrm{mL}$ ) for itraconazole, voriconazole, fluconazole, isavuconazole, and anidulafungin by EUCAST testing, suggesting in vitro resistance [23] and, therefore, a possibly non-WT strain with acquired resistance mechanism.

In this way, it is noteworthy that the emergence of S. schenckii and S. brasiliensis, classified as non-WT strains to itraconazole, amphotericin B, terbinafine, and voriconazole, is possibly less likely to respond the antifungal therapy and, therefore, potential-resistant isolates to these antifungal agents.

\section{Mechanisms for resistance development}

\section{Melanin production capacity}

Sporothrix species can produce three types of melanin [24]. DHN-melanin (I) is a synthesized substance by acetyl coenzyme A by polyketide standards, and L-DOPA-melanin (II) is synthesized by the L-3,4-dihydroxyphenylalanine (L-DOPA) pathway, wherein tyrosinases or laccases hydroxylate tyrosine 
Table 2 Susceptibility profile of Sporothrix schenckii and Sporothrix brasiliensis from different geographic origins by microdilution test and classified as wild-type (WT) and non-wild-type (non-WT) Sporothrix species

\begin{tabular}{|c|c|c|c|c|c|}
\hline \multirow[t]{2}{*}{ Origin of the Sporothrix spp. (n), according to the cited reference } & \multirow[t]{2}{*}{ Antifungal agents * } & \multicolumn{3}{|l|}{$\operatorname{MIC}(\mu \mathrm{g} / \mathrm{mL})$} & \multirow{2}{*}{$\begin{array}{l}\text { Profile } \\
\left(\mathrm{MIC}_{50} / \mathrm{MIC}_{90}\right)\end{array}$} \\
\hline & & Range & $\mathrm{MIC}_{50}$ & $\mathrm{MIC}_{90}$ & \\
\hline \multicolumn{6}{|l|}{ Sporothrix schenckii } \\
\hline \multirow[t]{4}{*}{ Worldwide (34) [16] } & AMB & $0.5-4$ & 4 & 4 & WT/WT \\
\hline & ITR & $1-32$ & 4 & 32 & non-WT/non-WT \\
\hline & POS & $0.5-16$ & 1 & 8 & WT/non-WT \\
\hline & VOR & $2-32$ & 32 & 32 & WT/WT \\
\hline \multirow[t]{4}{*}{ Brazil (39) [12] } & $\mathrm{AMB}$ & $1 \rightarrow 16$ & 8 & $>16$ & non-WT/non-WT \\
\hline & ITR & $0.25->16$ & 1 & 4 & WT/non-WT \\
\hline & POS & $0.06->16$ & 1 & 2 & WT/WT \\
\hline & VOR & $4->16$ & 16 & $>16$ & WT/n.s. \\
\hline \multirow[t]{4}{*}{ Argentina (13) [17] } & AMB & $0.5-4$ & 2 & 2 & WT/WT \\
\hline & ITR & $0.13-2$ & 2 & 2 & WT/WT \\
\hline & POS & $0.13-1$ & 0.5 & 1 & WT/WT \\
\hline & VOR & $8-16$ & 8 & 16 & $\mathrm{WT} / \mathrm{WT}$ \\
\hline \multicolumn{6}{|l|}{ Sporothrix brasiliensis } \\
\hline \multirow[t]{6}{*}{ Worldwide (23) [16] } & AMB & $1-4$ & 2 & 4 & WT/WT \\
\hline & ITR & $0.5-2$ & 0.5 & 1 & $\mathrm{WT} / \mathrm{WT}$ \\
\hline & POS & $0.25-1$ & 0.5 & 1 & WT/WT \\
\hline & VOR & $0.5-16$ & 4 & 8 & WT/WT \\
\hline & KET & $0.06-0.5$ & 0.125 & 0.25 & WT/WT \\
\hline & TERB & $0.06-0.25$ & 0.06 & 0.25 & WT/non-WT \\
\hline \multirow[t]{4}{*}{ Brazil (48) [18] } & AMB & $0.125-4$ & 1 & 2 & WT/WT \\
\hline & ITR & $0.125-2$ & 1 & 2 & WT/WT \\
\hline & VOR & $2-64$ & 16 & 64 & WT/non-WT \\
\hline & KET & $0.03-2$ & 0.25 & 1 & WT/WT \\
\hline \multirow[t]{4}{*}{ Brazil (22) [12] } & $\mathrm{AMB}$ & $1-8$ & 4 & 4 & $\mathrm{WT} / \mathrm{WT}$ \\
\hline & ITR & $0.25-4$ & 1 & 2 & WT/WT \\
\hline & POS & $0.5-2$ & 1 & 2 & $\mathrm{WT} / \mathrm{WT}$ \\
\hline & VOR & $2->16$ & 16 & $>16$ & WT/n.s. \\
\hline \multirow[t]{3}{*}{ Brazil (35) [14] } & AMB & $0.125-8$ & 1 & 4 & WT/WT \\
\hline & ITR & $0.25-8$ & 0.5 & 4 & WT/non-WT \\
\hline & TRB & $0.0156-4$ & 0.25 & 2 & non-WT/non-WT \\
\hline Brazil (29) [19] & ITR & $0.125 \rightarrow>16$ & 1 & $>16$ & WT/non-WT \\
\hline \multirow[t]{5}{*}{$\operatorname{Brazil}(23)[20]^{\dagger}$} & $\mathrm{AMB}$ & $0.25-4$ & 1 & 2 & WT/WT \\
\hline & ITR & $0.06-2$ & 0.5 & 0.5 & WT/WT \\
\hline & VOR & $1-16$ & 8 & 16 & WT/WT \\
\hline & KET & $0.03-1$ & 0.12 & 0.5 & $\mathrm{WT} / \mathrm{WT}$ \\
\hline & TRB & $0.01-0.5$ & 0.06 & 0.12 & WT/WT \\
\hline \multirow[t]{6}{*}{ Brazil (25) [21] } & AMB & $0.5-4$ & 2 & 4 & WT/WT \\
\hline & ITR & $1-2$ & 1 & 2 & WT/WT \\
\hline & POS & $0.5-1$ & 1 & 1 & WT/WT \\
\hline & VOR & $2->16$ & 8 & $>16$ & WT/n.s. \\
\hline & KET & $0.5-2$ & 1 & 2 & WT/WT \\
\hline & TRB & $0.03-0.12$ & 0.06 & 0.06 & WT/WT \\
\hline \multirow[t]{2}{*}{ Argentina (8) [17] } & AMB & $0.5-4$ & 2 & 4 & WT/WT \\
\hline & ITR & $0.25-2$ & 2 & 2 & WT/WT \\
\hline
\end{tabular}


Table 2 (continued)

\begin{tabular}{|c|c|c|c|c|c|}
\hline \multirow[t]{2}{*}{ Origin of the Sporothrix spp. $(n)$, according to the cited reference } & \multirow[t]{2}{*}{ Antifungal agents * } & \multicolumn{3}{|c|}{$\mathrm{MIC}(\mu \mathrm{g} / \mathrm{mL})$} & \multirow{2}{*}{$\begin{array}{l}\text { Profile } \\
\left(\mathrm{MIC}_{50} / \mathrm{MIC}_{90}\right)\end{array}$} \\
\hline & & Range & $\mathrm{MIC}_{50}$ & $\mathrm{MIC}_{90}$ & \\
\hline & POS & $0.25-2$ & 1 & 2 & WT/WT \\
\hline & VOR & $8-16$ & 8 & 16 & WT/WT \\
\hline & KET & $0.13-2$ & 1 & 2 & WT/WT \\
\hline & TRB & $0.13-0.5$ & 0.25 & 0.5 & non-WT/non-WT \\
\hline
\end{tabular}

*MIC, minimal inhibitory concentration; $A M B$, amphotericin B; ITR, itraconazole; POS, posaconazole; VOR, voriconazole; KTZ, ketoconazole; TRB, terbinafine; n.s., not specific

${ }^{\S}$ Sporothrix species tested by M38-A2 guideline of the Clinical and Laboratory Standards Institute [10] and classified as WT (susceptible isolates) and non-WT (potentially resistant isolates) and less likely to respond to the antifungal therapy, according to the epidemiological cutoff values (ECVs) proposed by Espinel-Ingroff et al. [3]; all MIC values of Sporothrix species were considered on mycelial phase and from papers in which the MIC range, $\mathrm{MIC}_{50}$ and $\mathrm{MIC}_{90}$ values were performed

${ }^{\dagger} \mathrm{MIC}_{50}$ and $\mathrm{MIC}_{90}$ values found by Stopiglia et al. [20] were calculated by Almeida-Paes et al. [21]

form dopaquinone via DOPA, which then self-oxidizes and polymerizes, resulting in a polyphenolic heteropolymer that is black. Finally, pyomelanin (III) is synthesized by L-tyrosine catabolism through p-hydroxyphenylpyruvate and homogentisic acid (HGA). These pigments are secondary metabolites consisting of phenolic and indolic monomers.

DHN-melanin synthesis does not require specific precursors, while the synthesis of L-DOPA and pyomelanin is increased in the presence of L-DOPA and L-tyrosine, respectively [24]. In the host, Sporothrix spp. synthetizes DHN and L-DOPA, which can protect fungi against antifungal and immune response, inhibiting phagocytosis and macrophage death [25] and suppress inflammation. Melanin biosynthesis in different species of Sporothrix spp. is not fully elucidated, but in general, the production of this pigment is higher and faster on $S$. brasiliensis than in S. schenckii.

The production of L-DOPA-melanin, pyomelanin, or DHNmelanin is associated with lower susceptibility to amphotericin B [26], with pyomelanin being more protective than L-DOPA-melanin. Besides, melanin protects Sporothrix species against the effect of terbinafine, an alternative antifungal to amphotericin B on sporotrichosis therapy. Although the biosynthesis pathways of DHN-melanin, L-DOPA-melanin, and pyomelanin are not fully elucidated on Sporothrix spp., the pathways are well established in Aspergillus fumigatus. In this fungal species, the DHN-melanin biosynthesis involves six genes (abr1, abr2, ayg1, arp1, arp2, and pks/alb1) located on the second chromosome [27]. Signals for expression of this cluster are unknown; however, it is believed to be related to conidiation. The synthesis of pyomelanin involves a cluster of six genes (hppD, hmgX, hmgA, fahA, maiA, and hmgR), also located on chromosome 2.

Unlike DHN-melanin synthesis, the pyomelanin synthesis is related to conidial germination, which is regulated by surface sensors, because some detect L-tyrosine or L-phenylalanine and others detect signs of stress on cell wall integrity, such as Wsc1, Wsc3, and MidA. These signals are transmitted via Rho
GTPases and mitogen-activated protein (MAP) kinases, which in A. fumigatus is composed of BcK1, Mkk2, and MpkA [27]. In another study [28], the genome analysis of S. schenckii and $S$. brasiliensis by homology showed that the enzymes pigmentbiosynthesis-protein yellowish-green 1, polyketide-synthase I and III, tetrahydroxyphenylpyruvate-trihydroxinaphtaleredutase, scytalone dehydratase, laccase, tyrosinase, and 4hydroxyphenylpyruvate dioxygenase were involved in the melanin metabolism.

For a better understanding of the effect of melanin production on Sporothrix species against the conventional antifungals, further in vitro, in vivo, and in silico studies should be performed, focusing on how DHN-melanin, L-DOPA-melanin, and pyomelanin synthesis occur. It is important to study the pathogenic Sporothrix species in different cell phases (yeast and mycelial phases), allowing the prospecting of new therapeutic targets.

\section{Genetic diversity}

Genetic diversity may have important ecological consequences at the population, community, and ecosystem levels [29], since it is related to a better adaptive capacity under selection pressure on Sporothrix species with high genetic diversity [30, 31]. High degrees of antifungal resistance were recognized among clinical clades of Sporothrix, which showed multidrug-resistant phenotypes [12]. In this way, genetic diversity seems to play a role in the acquisition of variability in the antifungal susceptibility. Phylogenetic and population genetic analyses showed that there is a purifying selection process in the recent evolutionary past of $S$. brasiliensis and $S$. globosa, which are the species with the least genetic polymorphism [16, 32-35]. In turn, S. schenckii s. str. showed high polymorphism in size and number of chromosomes [32], which is related to the higher variability in the antifungal susceptibility $[12,16]$, virulence [36], and genomic organization [32]. 
The genus Sporothrix has high intrinsic antifungal resistance [12]; therefore, studies have sought to understand the role of genetic diversity in the variability of antifungal susceptibility and virulence in Sporothrix sensu latu (s. l.). In vitro studies of antifungal susceptibility showed that $S$. brasiliensis and $S$. schenckii s. str. are more susceptible to antifungals than S. globosa and S. mexicana [16]. Among the clinical clades, $S$. brasiliensis and $S$. schenckii s. str. have been shown more in vitro susceptible to antifungals than S. globosa and $S$. mexicana [16]. In most clinical cases, $S$. brasiliensis responds well to antifungal drugs and shows lower MICs values $[3,12]$. However, due to selective pressure, some fungal isolates may be induced to show polymorphism in the number and size of chromosomes, which seem to play a role in the development of clones with antifungal resistance genes.

However, it has recently been shown that isolates of S. brasiliensis recovered from cats and dogs living in the extreme south of Brazil showed low in vitro susceptibility to branded and compounded itraconazole formulations [37], characterizing them as itraconazole-resistant isolates. Considering that $S$. brasiliensis has at least two distinct sources in Brazil [34], the emergence of S. brasiliensis in Southern Brazil with antifungal resistance seems to be related to the genetic diversity. Phylogenetic analysis showed that S. brasiliensis strains from the Rio Grande do Sul differed from the strains recovered from cases in São Paulo, Minas Gerais, and Paraná, which share the same genotype of the Rio de Janeiro outbreak [34]. Moreover, genetic diversity is lower in S. brasiliensis in comparison with S. schenckii s. str. [33].

It is known that the prolonged exposure to antifungals and the host immunity may exert selective pressure on pathogenic fungi [30]. Although this phenomenon can occur spontaneously, it has also been observed in fungi exposed to antifungal agents, and this finding supports the involvement of chromosomal polymorphism in Sporothrix species for the acquisition of variability of antifungal susceptibility profiles [32, 34]. Changes in the genomic architecture and the emergence of an abnormal number of chromosomes were noted in triazoles-resistant Candida albicans and Cryptococcus neoformans [38-40]. The abnormal number of chromosomes is called aneuploidy, and offer additional copies of resistance genes, leading to the manifestation of a phenotype with antifungal resistance [38, 39] and quick adaptation [40]. These findings seem to play a role in the acquisition of antifungal resistance among Sporothrix species.

The molecular mechanisms involved in antifungal resistance are complex and still poorly understood. One of the tools suggested to better understand the mechanisms involved in the intrinsic and acquired resistance in the pathogenic species of Sporothrix species is the study of the differential expression of genes through transcriptomics and proteomics, which are still scarce. Further studies must be carried out to understand the mechanisms involved in the resistance of Sporothrix species under pressure by antifungals.

\section{Mutations in cytochrome P450 monooxygenase}

It is known that the azole antifungal agents act by inhibiting cytochrome P450 monooxygenases, particularly the P450 CYP51 that is involved in the ergosterol biosynthesis [41, 42]. Itraconazole is the first-choice antifungal for sporotrichosis treatment, whereas ketoconazole was found to be inefficient. Therefore, Matowane et al. [42] performed an in silico analysis with the focus on CYP51 to better elucidate the ketoconazole-resistance of $S$. schenckii. In this study, the presence of CYP51 in S. schenckii coupled with effective treatment with itraconazole suggests that there is inhibition of CYP51, the target of itraconazole. In silico analysis of CYP51 also revealed that mutations at the itraconazolebinding site, especially T230N, are related to increased azole resistance, as demonstrated with T229A equivalent mutation in $C$. albicans. The amino acid located at the entrance of the channel to the active site plays a key role related to resistance to ketoconazole. This study revealed new perspectives for a better understanding of the resistance of $S$. schenckii to azole class [42].

\section{Concluding remarks}

Sporothrix species from human and animal cases have shown ability in developing antifungal resistance to conventional antifungal, and $S$. brasiliensis is the fungal species with a high ability to acquire mutational or resistance mechanism. From the reviewed studies, few studies have focused on the mechanism of development of antifungals resistance. Although this ability is not fully elucidated, the resistance development on Sporothrix species was related to the melanin production capacity (DHN-melanin, L-DOPA-melanin, and pyomelanin), to the low genetic diversity possibly due to the abnormal number of chromosomes, and to the mutations in cytochrome P450. In this sense, further studies should be carried out targeting gene expression for the development of antifungal resistance to prospect new therapeutic targets.

\section{Compliance with ethical standards}

Conflict of interest The authors declare that they have no conflict of interest.

Ethics approval Not applicable. This paper does not contain any studies with experimental animals.

Informed consent Not applicable. This paper does not contain any studies with human participants performed by any of the authors. 


\section{References}

1. Fischman Gompertz O, Rodrigues AM, Fernandes GF, Bentubo HD, de Camargo ZP, Petri V (2016) Atypical clinical presentation of sporotrichosis caused by Sporothrix globosa resistant to itraconazole. Am J Trop Med Hyg 94:1218-1222. https://doi.org/ 10.4269/ajtmh.15-0267

2. Vettorato R, Heidrich D, Fraga F, Ribeiro AC, Pagani DM, Timotheo C, Amaro TG, Vettorato G, Scroferneker ML (2017) Sporotrichosis by Sporothrix schenckii senso stricto with itraconazole resistance and terbinafine sensitivity observed in vitro and in vivo: case report. Med Mycol Case Rep 19:18-20. https:// doi.org/10.1016/j.mmcr.2017.10.001

3. Espinel-Ingroff A, Abreu DPB, Almeida-Paes R, Brilhante RSN, Chakrabarti A, Chowdhary A, Hagen F, Córdoba S, Gonzalez GM, Govender NP, Guarro J, Johnson EM, Kidd SE, Pereira SA, Rodrigues AM, Rozental S, Szeszs MW, Ballesté Alaniz R, Bonifaz A, Bonfietti LX, Borba-Santos LP, Capilla J, Colombo AL, Dolande M, Isla MG, Melhem MSC, Mesa-Arango AC, Oliveira MME, Panizo MM, Pires de Camargo Z, ZancopeOliveira RM, Meis JF, Turnidge J (2017) International study of MIC/MEC distributions for definition of epidemiological cutoff values for Sporothrix species identified by molecular methods. Antimicrob Agents Chemother 61:e01057-e01017. https://doi. org/10.1128/AAC.01057-17

4. Guterres KA, de Matos CB, Osório Lda G, Schuch ID, Cleff MB (2014) The use of (1-3) $\beta$-glucan along with itraconazole against canine refractory sporotrichosis. Mycopathologia 177:217-221. https://doi.org/10.1007/s11046-014-9736-6

5. Rodrigues AM, Della Terra PP, Gremião ID, Pereira SA, OrofinoCosta R, de Camargo ZP (2020) The threat of emerging and reemerging pathogenic Sporothrix species. Mycopathologia 1-30. https://doi.org/10.1007/s11046-020-00425-0

6. Orofino-Costa R, Macedo PM, Rodrigues AM, BernardesEngemann AR (2017) Sporotrichosis: an update on epidemiology, etiopathogenesis, laboratory and clinical therapeutics. An Bras Dermatol 92:606-620. https://doi.org/10.1590/abd1806-4841. 2017279

7. Govender NP, Maphanga TG, Zulu TG, Patel J (2015) An outbreak of Lymphocutaneous Sporotrichosis among mine-workers in South Africa. PLoS Negl Trop Dis 9:e0004096. https://doi.org/10.1371/ journal.pntd.0004096

8. Da Rocha RFDB, Schubach TMP, Pereira SA, dos Reis ÉG, Carvalho BW, Gremião IDF (2018) Refractory feline sporotrichosis treated with itraconazole combined with potassium iodide. J Small Anim Pract 59:720-721. https://doi.org/10.1111/jsap.12852

9. Gremião I, Schubach T, Pereira S, Rodrigues A, Honse C, Barros M (2011) Treatment of refractory feline sporotrichosis with a combination of intralesional amphotericin B and oral itraconazole. Aust Vet J 89:346-351. https://doi.org/10.1111/j.1751-0813.2011. 00804.x

10. Clinical and Laboratory Standard Institute (2008) Reference method for broth dilution antifungal susceptibility testing of filamentous fungi: approved M38-a, 2nd edn. CLSI, Wayne, $52 \mathrm{pp}$

11. Arendrup MC, Cuenca-Estrella M, Lass-Flörl C, Hope W, Howard SJ, the Subcommittee on Antifungal Susceptibility Testing (AFST) of the ESCMID European Committee for Antimicrobial Susceptibility Testing (EUCAST) (2015) Method for the determination of broth dilution minimum inhibitory concentrations of antifungal agents for conidia forming moulds. EUCAST Definitive Document EDef 9.2. European Society of Clinical Microbiology and Infectious Diseases, Taufkirchen $24 \mathrm{pp}$

12. Rodrigues AM, de Hoog GS, de Cássia PD et al (2014) Genetic diversity and antifungal susceptibility profiles in causative agents of sporotrichosis. BMC Infect Dis 14:219. https://doi.org/10.1186/ 1471-2334-14-219

13. Waller SB, Madrid IM, Hoffmann JF, Picoli T, Cleff MB, Chaves FC, Faria RO, Meireles MCA, Braga de Mello JR (2017) Chemical composition and cytotoxicity of extracts of marjoram and rosemary and their activity against Sporothrix brasiliensis. J Med Microbiol 66:1076-1083. https://doi.org/10.1099/jmm.0.000517

14. Sanchotene KO, Brandolt TM, Klafke GB, Poester VR, Xavier MO (2017) In vitro susceptibility of Sporothrix brasiliensis: comparison of yeast and mycelial phases. Med Mycol 55:869-876. https://doi. org/10.1093/mmy/myw143

15. Waller SB, Peter CM, Hoffmann JF, Picoli T, Osório LG, Chaves F, Zani JL, de Faria RO, de Mello JRB, Meireles MCA (2017) Chemical and cytotoxic analyses of brown Brazilian propolis (Apis mellifera) and its in vitro activity against itraconazoleresistant Sporothrix brasiliensis. Microb Pathog 105:117-121. https://doi.org/10.1016/j.micpath.2017.02.022

16. Marimon R, Serena C, Gené J, Cano J, Guarro J (2008) In vitro antifungal susceptibilities of five species of Sporothrix. Antimicrob Agents Chemother 14:732-734. https://doi.org/10.1128/AAC. 01012-07

17. Córdoba S, Isla G, Szusz W, Vivot W, Hevia A, Davel G, Canteros CE (2018) Molecular identification and susceptibility profile of Sporothrix schenckii sensu lato isolated in Argentina. Mycoses 61:441-448. https://doi.org/10.1111/myc.12760

18. Brilhante RS, Rodrigues AM, Sidrim JJ et al (2016) In vitro susceptibility of antifungal drugs against Sporothrix brasiliensis recovered from cats with sporotrichosis in Brazil. Med Mycol 54:275279. https://doi.org/10.1093/mmy/myv039

19. Waller SB, Madrid IM, Silva AL, Dias de Castro LL, Cleff MB, Ferraz V, Meireles MCA, Zanette R, de Mello JRB (2016) In vitro susceptibility of Sporothrix brasiliensis to essential oils of Lamiaceae family. Mycopathologia 181:857-863. https://doi.org/ 10.1007/s11046-016-0047-y

20. Stopiglia CDO, Magagnin CM, Castrillón MR et al (2014) Antifungal susceptibilities and identification of species of the Sporothrix schenckii complex isolated in Brazil. Med Mycol 52: 56-64. https://doi.org/10.3109/13693786.2013.818726

21. Almeida-Paes R, Oliveira MME, Freitas DFS, do Valle ACF, Gutierrez-Galhardo MC, Zancope-Oliveira RM (2017) Refractory sporotrichosis due to Sporothrix brasiliensis in humans appears to be unrelated to in vivo resistance. Med Mycol 55:507-517. https:// doi.org/10.1093/mmy/myw103

22. Gutierrez-Galhardo MC, Zancopé-Oliveira RM, Monzón A, Rodriguez-Tudela JL, Cuenca-Estrella M (2010) Antifungal susceptibility profile in vitro of Sporothrix schenckii in two growth phases and by two methods: microdilution and E-test. Mycoses 53:227-231. https://doi.org/10.1111/j.1439-0507.2009.01701.x

23. Wolff D, Feldt T, Reifenberger J, Sebald H, Bogdan C (2018) Closing the brief case: cutaneous Sporotrichosis in an Immunocompetent patient after travel to Peru. J Clin Microbiol 56:e01961-e01917. https://doi.org/10.1128/JCM.01961-17

24. Almeida-Paes R, Frases S, Araújo GS et al (2012) Biosynthesis and functions of a melanoid pigment produced by species of the Sporothrix complex in the presence of L-tyrosine. Appl Environ Microbiol 78:8623-8630. https://doi.org/10.1128/AEM.02414-12

25. Romero-Martinez R, Wheeler M, Guerrero-Plata A, Rico G, Torres-Guerrero H (2000) Biosynthesis and functions of melanin in Sporothrix schenckii. Infect Immun 68:3696-3703. https://doi. org/10.1128/IAI.68.6.3696-3703.2000

26. Almeida-Paes R, Figueiredo-Carvalho MH, Brito-Santos F, Almeida-Silva F, Oliveira MM, Zancopé-Oliveira RM (2016) Melanins protect Sporothrix brasiliensis and Sporothrix schenckii from the antifungal effects of terbinafine. PLoS One 11:e0152796. https://doi.org/10.1371/journal.pone.0152796 
27. Tsai H, Wheeler MH, Chang YC, Chang YC, Kwon-Chung KJ (1999) A developmentally regulated gene cluster involved in conidial pigment biosynthesis in Aspergillus fumigatus. J Bacteriol 181:6469-6477

28. Teixeira MM, de Almeida LGP, Kubitschek-Barreira P, Alves FL, Kioshima ÉS, Abadio AKR, Fernandes L, Derengowski LS, Ferreira KS, Souza RC, Ruiz JC, de Andrade NC, Paes HC, Nicola AM, Albuquerque P, Gerber AL, Martins VP, Peconick LDF, Neto A, Chaucanez CB, Silva PA, Cunha OL, de Oliveira FFM, dos Santos TC, Barros ALN, Soares MA, de Oliveira LM, Marini MM, Villalobos-Duno H, Cunha MML, de Hoog S, da Silveira JF, Henrissat B, Niño-Vega GA, Cisalpino PS, MoraMontes HM, Almeida SR, Stajich JE, Lopes-Bezerra LM, Vasconcelos ATR, Felipe MSS (2014) Comparative genomics of the major fungal agents of human and animal Sporotrichosis: Sporothrix schenckii and Sporothrix brasiliensis. BMC Genomics 15:1-22. https://doi.org/10.1186/1471-2164-15-943

29. De Oliveira MM, Veríssimo C, Sabino R et al (2014) First autochthone case of sporotrichosis by Sporothrix globosa in Portugal. Diagn Microbiol Infect Dis 78:388-390. https://doi.org/10.1016/j. diagmicrobio.2013.08.023

30. Gong J, Zhang M, Wang Y, Li R, He L, Wan Z, Li F, Zhang J (2019) Population structure and genetic diversity of Sporothrix globosa in China according to 10 novel microsatellite loci. J Med Microbiol 68:248-254. https://doi.org/10.1099/jmm.0.000896

31. Huang L, Gao W, Giosa D, Criseo G, Zhang J, He T, Huang X, Sun J, Sun Y, Huang J, Zhang Y, Brankovics B, Scordino F, D'Alessandro E, van Diepeningen A, de Hoog S, Huang H, Romeo O (2016) Whole-genome sequencing and in silico analysis of two strains of Sporothrix globosa. Genome Biol Evol 8:32923296. https://doi.org/10.1093/gbe/evw230

32. Sasaki AA, Fernandes GF, Rodrigues AM, Lima FM, Marini MM, dos Feitosa LS, de Melo Teixeira M, Felipe MSS, da Silveira JF, de Camargo ZP (2014) Chromosomal polymorphism in the Sporothrix schenckii complex. PLoS One 14:e86819. https://doi.org/10.1371/ journal.pone.0086819

33. Rodrigues AM, de Hoog GS, Zhang Y, Camargo ZP (2014) Emerging sporotrichosis is driven by clonal and recombinant Sporothrix species. Emerg Microbes Infect 3(5):e32. https://doi. org/10.1038/emi.2014.33

34. Rodrigues AM, de Melo TM, de Hoog GS et al (2014) Phylogenetic analysis reveals a high prevalence of Sporothrix brasiliensis in feline sporotrichosis outbreaks. PLoS Negl Trop Dis 7(6):e2281. https://doi.org/10.1371/journal.pntd.0002281
35. Rangel-Gamboa L, Martínez-Hernandez F, Maravilla P, ArenasGuzmán R, Flisser A (2016) Update of phylogenetic and genetic diversity of Sporothrix schenckii sensu lato. Med Mycol 54(3): 248-255. https://doi.org/10.1093/mmy/myv096

36. Fernandes GF, dos Santos PO, Rodrigues AM, Sasaki AA, Burger E, de Camargo ZP (2013) Characterization of virulence profile, protein secretion and immunogenicity of different Sporothrix schenckii sensu stricto isolates compared with S. globosa and S. brasiliensis species. Virulence 4:241-249. https://doi.org/10. 4161/viru.23112

37. Waller SB, Ripoll MK, Madrid IM, Acunha T, Cleff MB, Chaves FC, de Mello JRB, de Faria RO, Meireles MCA (2020) Susceptibility and resistance of Sporothrix brasiliensis to branded and compounded itraconazole formulations. Braz J Microbiol. https://doi.org/10.1007/s42770-020-00280-7

38. Harrison BD, Hashemi J, Bibi M, Pulver R, Bavli D, Nahmias Y, Wellington M, Sapiro G, Berman J (2014) A tetraploid intermediate precedes aneuploid formation in yeasts exposed to fluconazole. PLoS Biol 12:e1001815. https://doi.org/10.1371/journal.pbio. 1001815

39. Hill JA, Ammar R, Torti D, Nislow C, Cowen LE (2013) Genetic and genomic architecture of the evolution of resistance to antifungal drug combinations. PLoS Genet 9:e1003390. https://doi.org/10. 1371/journal.pgen.1003390

40. Ni M, Feretzaki M, Li W, Floyd-Averette A, Mieczkowski P, Dietrich FS, Heitman J (2013) Unisexual and heterosexual meiotic reproduction generate aneuploidy and phenotypic diversity de novo in the yeast Cryptococcus neoformans. PLoS Biol 11:e1001653. https://doi.org/10.1371/journal.pbio.1001653

41. Kelly SL, Lamb DC, Corran AJ, Baldwin BC, Kelly DE (1995) Mode of action and resistance to azole antifungals associated with the formation of 14 alpha-methylergosta-8,24(28)-dien-3 beta, 6 alpha-diol. Biochem Biophys Res Commun 207:910-915. https:// doi.org/10.1006/bbrc.1995.1272

42. Matowane RG, Wieteska L, Bamal HD, Kgosiemang IKR, van Wyk M, Manume NA, Abdalla SMH, Mashele SS, Gront D, Syed K (2018) In silico analysis of cytochrome P450 monooxygenases in chronic granulomatous infectious fungus Sporothrix schenckii: special focus on CYP51. Biochim Biophys Acta, Proteins Proteomics 1866:166-177. https://doi.org/10.1016/j. bbapap.2017.10.003

Publisher's note Springer Nature remains neutral with regard to jurisdictional claims in published maps and institutional affiliations. 